PALAVRAS. Revista de Epistemología, Metodología y Ética del Psicoanálisis

ISSN: 2468-9831

www.revistas.unlp.edu.ar/palavras

palavras@outlook.com.ar

Argentina

\title{
ACERCA DEL TRATAMIENTO PSICOANALÍTICO
}

DOI $10.24215 / 24689831 \mathrm{e} 002$

\section{Luis Chiozza}

\section{Abstract}

Resumen

This paper exposes the main features of Se exponen las principales características del psychoanalytic treatment and the reasons that lead tratamiento psicoanalitico y las razones que llevan a to a patient to psychoanalysis. It unfold and relate un paciente a psicoanalizarse. Se despliegan y the notions of psychic conflict, transfer and relacionan las nociones de conflicto psíquico, framing, from an integrative anthropological transferencia y encuadre, desde una concepción conception and considering the difficulties that antropológica integradora $\mathrm{y}$ atendiendo a las psychoanalytic practice must overcome to realized. dificultades que la práctica psicoanalítica debe sobrellevar pare efectivizarse.

Key words: Psychoanalytic methodology - psychic conflict - Transference - setting

Palabras clave: Metodología psicoanalítica - Conflicto psíquico - Transferencia - Encuadre

\section{Cómo citar este artículo:}

Chiozza, L. (2015). Acerca del tratamiento psicoanalítico. Palavras. Revista de Epistemología, Metodología y Ética del Psicoanálisis, 1(1), 17-59. Recuperado de www.revistas.unlp.edu.ar/palavras 


\section{ACERCA DEL TRATAMIENTO PSICOANALÍTICO Luis Chiozza *}

\section{¿De dónde surge la necesidad del tratamiento?}

Algunas personas recurren al psicoanálisis porque, anímicamente, "se sienten mal", o porque en su vida se repiten cosas que les producen sufrimientos y que no logran superar. Otras concurren porque presentan sintomas que atribuyen a un trastorno en las funciones del cuerpo y alguien les ha dicho, o ellas mismas han pensado, que esos trastornos dependen de lo que les sucede en el alma. Quienes se psicoanalizan suelen decir que lo hacen porque tienen problemas que no pueden resolver sin ayuda; y cabe preguntarse, entonces: ¿de qué depende el que no puedan "arreglarse" sin recurrir a que alguien "les ofrezca una mano"?

Encontramos una respuesta fundamental cuando comprendemos que sería más exacto decir que esos supuestos problemas son, en realidad, dificultades. Las dificultades surgen cuando no encontramos la manera de obtener lo que deseamos, y arrecian cuando no logramos evitar que las cosas que más nos importan nos hagan sufrir. Solemos llamar problemas a las dificultades porque asumimos que se trata de acciones dificiles que se pueden alcanzar razonando; y aquí, en este punto, reside la cuestión esencial. Los procedimientos razonables permiten resolver las incógnitas cuando los datos disponibles son suficientes; y sucede que, precisamente, las dificultades que el psicoanálisis se propone resolver provienen de premisas que operan de manera inconsciente, es decir, de asuntos que, por estar reprimidos, se ignoran.

Nietzsche ha escrito: "Muy trágicas han de ser las razones que hacen de un hombre un filósofo". Teniendo en cuenta esa frase, algunas veces

\footnotetext{
* Médico psicoanalista. Actualmente dirige el Instituto de Docencia e Investigación de la Fundación Luis Chiozza y el Centro Weizsaecker de Consulta Médica. E-mail: luis@chiozza.com.
} 
hemos sostenido que "las razones" que conducen a un tratamiento psicoanalítico, aunque no suelen llegar a ser trágicas, son siempre serias. De más está decir que su seriedad no permanece en la consciencia de manera constante, sino que sufre los avatares del apremio que experimentamos en la vida. De modo que la cuestión no sólo reside en que el psicoanálisis puede ser necesario, sino también en que la primera condición para que sea posible es la consciencia de su necesidad.

Cuando el apremio disminuye, todo parece más fácil, y tendemos a olvidarnos de las circunstancias aciagas. Nada tiene de extraño que, como dice el proverbio, sólo nos acordemos de Santa Bárbara cuando llueve, porque nuestra consciencia es un órgano destinado a resolver dificultades; y la memoria, o la noticia, de las cosas cuya urgencia pierde actualidad tiende a guardarse en un lugar que permanece lejos de la atención consciente.

Cuando el apremio, en cambio, aumenta, el desasosiego también se incrementa, y la memoria, o la noticia, de las cosas que ya se han resuelto pierde actualidad, y no siempre alcanza para infundirnos la confianza necesaria para emprender un esfuerzo que, como es natural, lleva siempre implícita la postergación de una satisfacción inmediata.

En el primer caso, con el apremio disminuido, un alivio transitorio suele conducir a la idea de que no necesitamos ayuda, y en el segundo, en que el apremio acosa, la impaciencia y el sufrimiento intenso a veces nos inclinan a negar que la ayuda sea posible, y que el esfuerzo vale la pena. El psicoanálisis "posible" transcurre, pues, entre dos escollos, un apremio insuficiente para mantener en la consciencia la necesidad del empeño, y otro, excesivo, que también puede conducir a rechazarlo.

Es importante mencionar una circunstancia esencial que colabora para que la persona que podría beneficiarse con un tratamiento psicoanalítico procure evitarlo o sustituirlo con algún otro tipo de medicina. Cuando se piensa, simplificando la cuestión, que la enfermedad 
es un proceso únicamente físico -que se curará con la cirugía o con el efecto de un fármaco, por ejemplo-, le corresponde al médico luchar, con su técnica terapéutica, "contra" la enfermedad, mientras que el paciente, en cambio, sólo "se presta" para esa tarea cuya responsabilidad recae, casi exclusivamente, sobre el profesional que la emprende. Las fuerzas fisicas no tienen intenciones ni sentido, nada en el mundo físico puede ser moral o inmoral. A las moléculas no les importa "estar bien" o "estar mal". De modo que el que sufre afectado por un proceso "físico" -frente al que asume que no lo domina y que no lo puede prever- es, por definición, irresponsable e inocente.

Es cierto que el médico, para poder curar, se ve obligado, una y otra vez, a recurrir a la colaboración del enfermo, y necesita, entonces, ser capaz de una influencia psíquica que no siempre es fácil, pero, dado que su formación profesional no lo ha preparado para ese desempeño, suele ejercerla de un modo muy rudimentario. Señalemos, de paso, la frecuencia con que algunos pacientes, cuando se psicoanalizan, transfieren sobre la psicoterapia ese "modelo médico" que les facilita substraer una gran parte de su responsabilidad en cuanto al logro de los resultados que esperan.

Volvamos otra vez sobre el hecho de que otras técnicas terapéuticas no requieren que la consciencia del paciente participe en cada uno de los íntimos pormenores de la acción que el médico o la droga ejercen para curarlo. Durante el tratamiento psicoanalítico, en cambio, tal como sucede con los procesos de aprendizaje -que deben cambiar los hábitos adquiridos-, el resultado depende, en lo fundamental, de una participación consciente del psicoanalizado que le demanda un esfuerzo "contranatural" y sostenido. Se trata, sin duda, de un empeño que debe ser considerado. Sin embargo, debemos asumir que si elegimos -siguiendo el ejemplo del gran Alejandro- cortar quirúrgicamente el nudo gordiano, hemos renunciado a desembrollar la madeja, y que de nada vale, entonces, derramar lágrimas por la cantidad del hilo de nuestra vida que, enterrando recuerdos, desechamos. 


\section{El conflicto inconsciente}

Suele decirse que la contribución más valiosa de Freud, que aun sus detractores aceptan, ha sido su reconocimiento de una vida psíquica inconsciente. Pero en esto el psicoanálisis ha tenido numerosos precursores. Ya San Agustín decía, por ejemplo: "Lo sabes pero ignoras que lo sabes". No cabe duda, en cambio, acerca de la trascendencia alcanzada por el haber insistido en el hecho de que una parte muy importante de nuestros motivos permanece inconsciente por obra de una fuerza que los mantiene reprimidos.

El descubrimiento freudiano de esa fuerza represora florece rápidamente en una serie de conceptos fructíferos que enriquecen el panorama de la vida psíquica. La represión no procede "porque sî", actúa para liberar a la consciencia de un conflicto entre fuerzas en pugna. En un principio, el esquema del conflicto fue sencillo: lo que se reprime es un deseo, y la razón que conduce a reprimirlo es la moral.

Sucede, sin embargo, que la represión no siempre es exitosa, y lo reprimido suele retornar bajo una forma nueva. En ella el deseo, oculto, se realiza perturbado y convertido en alguno de los trastornos que el joven Freud procuraba esclarecer. De alli surge la primera y fundamental finalidad del psicoanálisis: se trata de conducir a la consciencia el litigio reprimido que retorna produciendo un trastorno, porque eso ayudará para conciliarlo y resolverlo de una mejor manera.

Años después, un gran médico alemán, Víctor von Weizsaecker lo resumirá en una frase escueta: "Sí, pero no asî". En la segunda parte de esa frase, "así" alude a la enfermedad, mientras que en el "sî" de la primera parte se admite que la enfermedad esconde un motivo justificado y comprensible. Freud dice algo semejante cuando afirma que la enfermedad es un oponente digno, y también cuando sostiene que así como el molusco 
construye una perla sobre un grano de arena, todo delirio contiene en su interior el residuo de una "verdad" que forma parte de una historia.

La práctica psicoanalitica condujo, ya desde sus mismos inicios, a descubrir que la represión se presenta siempre, en el tratamiento, bajo la forma de una resistencia que es necesario vencer. Allí radica, precisamente, una de las razones fundamentales que nos conducen a decir, acerca del psicoanálisis, que, a pesar de que no tenemos algo mejor “en su género", lo acompañan esfuerzos, dificultades y penas. El desarrollo de un procedimiento efectivo para lidiar con esa resistencia pasó por diversas etapas.

En los comienzos de su técnica psicoanalitica, Freud procuraba hipnotizar a sus pacientes para que recordaran los acontecimientos traumáticos reprimidos. Más tarde recurrió a la llamada "sugestión en estado de vigilia", cuando, presionando con sus dos manos sobre la cabeza del enfermo, le aseguraba que al retirarlas le surgiría una ocurrencia que debía comunicar. Muy pronto, sin embargo, la experiencia lo condujo a sustituir esos dos procedimientos por otro denominado "asociación libre", que consistia en pedirle al paciente que comunicara, sin omisión alguna, todo lo que se le fuera ocurriendo, aunque le pareciera nimio o absurdo. Este último procedimiento constituye una "regla fundamental" del tratamiento, y en nuestros días continúa vigente.

La fuerza principal de la resistencia con la que tropezamos deriva de que, en algún lugar escondido, se conserva el registro del dolor que el conflicto original produjo y del alivio obtenido cuando se logró alejar de la consciencia una de las "partes" que alli sostenían el litigio. Dos circunstancias contribuyen, sin embargo, para que pueda emprenderse la tarea de rescatar lo reprimido renovando un intento de conciliación que antes falló. Una consiste en la convicción intelectual y adquirida (que la confianza que puede depositarse en el psicoanalista refuerza) de que el conflicto original suele ser propio de una circunstancia antigua que hoy es anacrónica, es decir, incongruente con la situación actual. La otra, más 
importante, se da cuando existen experiencias anteriores en las cuales el hacer consciente algo inconsciente reprimido condujo a incrementar el bienestar.

Lo que en un principio la teoría psicoanalítica concibió como un conflicto binario, entre los impulsos instintivos "naturales" y las normas que impone la cultura, permitió distinguir entre la neurosis, en donde los impulsos reprimidos adquieren una forma insalubre, y la perversión, en la cual la represión de la norma moral genera las conductas que se observan en la psicopatía.

Si observamos el recorrido que realizó Freud, desde sus primeros trabajos hasta los últimos, vemos que las fuerzas en pugna fueron quedando ubicadas en representantes distintos: el ello, el superyó, la realidad "exterior", o los hábitos que conforman el carácter del yo. Además, en la medida en que descubrimos que las desarmonías entre la naturaleza y la cultura no son forzosamente "naturales" -porque fuimos encontrando cada vez más naturaleza en la cultura y más cultura en la naturaleza-, nos fue quedando claro que las normas no sólo nos llegan desde el superyó o desde las costumbres que rigen en la sociedad en que vivimos. También funcionan como normas, que debemos conciliar, los impulsos instintivos, las exigencias de la realidad, o inclusive nuestros propios rasgos de carácter, configurados como hábitos, como procedimientos antiguos que en su momento consideramos efectivos, cuando ya no nos conforman y los queremos cambiar.

\section{Los valores, los afectos y los actos}

Las normas son valores; son procedimientos que funcionan como lemas a los cuales, con mayor o con menor fortuna, queriendo o sin querer, alguna vez nos adherimos. Weizsaecker (2005), con intuición, perspicacia y lucidez, lo ha dejado bien claro. Vivimos en un mundo "óntico", en donde las cosas físicamente son, y podemos imaginarlas 
carentes, en sí mismas, de significancia, indiferentes a lo que les sucede; pero en nuestra consciencia también habita un mundo "pático", en el doble sentido de pasión y padecer. Se trata de un mundo de afectos y procedimientos en el cual lo que nos hace bien se diferencia de lo que nos hace mal.

En ese mundo en el cual las cosas adquieren de ese modo, mediante esa diferencia, una importancia, un significado y un valor, Weizsaecker identifica los cinco verbos alemanes que constituyen los parámetros que definen las vicisitudes de la existencia pática. Son verbos auxiliares, ya que se utilizan para referirse a las acciones que otros verbos designan. Los usamos en sus formas afirmativa, negativa o interrogativa; en sus tiempos pretérito, presente y futuro; y también en los distintos modos (indicativo, subjuntivo, imperativo o condicional). Esto puede darnos una idea de la enorme cantidad de matices que pueden llegar a expresar a través de sus combinaciones.

En nuestra lengua carecemos de las palabras con que el idioma alemán diferencia entre deber como “estar obligado" (müssen) o como deuda moral (sollen) y poder como capacidad (können) o como "tener permiso" (dürfen). De modo que las cinco categorias que configuran el pentagrama pático de Weizsaecker, müssen, sollen, können, dürfen, y wollen (querer), quedan en nuestro idioma reducidas a tres: deber, poder y querer.

Si tenemos en cuenta que tanto el "estar obligado" como la capacidad parecen aludir a la perentoriedad que asociamos a los aspectos materiales de la existencia, y la deuda moral o el "tener permiso" se inclinan, en cambio, hacia los componentes espirituales de la vida, no cabe duda de que también dentro del querer podriamos establecer una análoga diferencia entre necesitar y desear. Freud contribuye a establecer esa diferencia cuando afirma que la necesidad no admite con la misma ductilidad que el deseo la sustitución de los objetivos a través de los cuales alcanza su satisfacción. 
Las categorías páticas fluctúan, se mezclan, se combinan o se sustituyen entre sí. Bastan unos pocos ejemplos para descubrir, con sorpresa, que las cinco categorías páticas impregnan de manera ubicua nuestro mundo cotidiano y se hallan presentes en todas y cada una de las sesiones de un proceso psicoanalítico. Introducen el alma en la realidad "física" en la cual vivimos, y en la "lógica" de una relación causal, con los principios intencionales que caracterizan a los personajes que habitan nuestro mundo psíquico. "Si quisiera, podría" o, también, "aunque quiera, no podré”. “¿Quiero hacer lo que hago?” Si me da culpa querer, podré creer que me obligan. “¿Puedo lo que quiero?” Si me avergüenza mi impotencia, podré creer que no me dejan, que no me dan permiso. "¿Puedo hacer lo que debo?" Si creo que no puedo, podré pretender que no debo. Si no quiero hacer lo que debo, también podré creer que no me dan permiso. Si siento que "no debo querer hacer lo que no puedo", y siento que "no puedo dejar de quererlo", puedo creer que no me dan permiso o, también, que "no quiero pero me obligan a hacer lo que no puedo".

\section{Tres maneras de la vida}

Dedicamos un libro (Chiozza, 2009) a explorar cómo esos tres órganos -que derivan respectivamente del mesodermo, el endodermo y el ectodermo embrionarios- simbolizan los distintos tipos de acciones que caracterizan al comportamiento de un organismo en su entorno. Como expresión de esas "tres maneras de la vida", algunas de tales acciones, vegetativas, configuran sentimientos; otras, que pertenecen a lo que denominamos "vida de relación", se vinculan estrechamente con la voluntad o con el pensamiento.

No cabe duda de que el querer ("cardíaco") es fundamentalmente un sentimiento, el poder ("hepático") traza los límites de la voluntad, y el deber ("cerebral") se configura como un procedimiento normativo que 
constituye la meta de todo pensamiento. Puede decirse también que, en un cierto sentido, el querer, cardíaco, coincide, desde un punto de vista, con la instancia que Freud denominaba "ello"; el poder, hepático, con el "yo"; y el deber, cerebral, con el "superyó". Se completa de ese modo el esbozo de un esquema que nos permite comprender en el lenguaje de la vida cotidiana (metahistórico) los conflictos entre instancias (metapsicológicas) con los que se enfrenta la consciencia.

Antes de proseguir por ese camino esquemático, conviene aclarar que, si bien las categorias páticas y las tres maneras de la vida existen dado que los verbos auxiliares que aluden a sus funciones o los usos del lenguaje certifican su existencia-, también es cierto que, más allá de los esquemas que podamos trazar, nunca funcionan aisladas y se interpenetran en múltiples combinaciones, influyéndose y transformándose reciprocamente. Ortega, en El hombre a la defensiva (1963), escribe: Todo concepto es por su naturaleza una exageración, y en ese sentido una falsificación. [...] Este carácter de ficción que tiene el concepto, ésta su consciente falsedad, es su virtud mayor. [...] La exageración es el momento de creación que tiene el pensamiento. [...] La verdad resulta cuando al trasluz de ese mundo ficticio miramos la realidad.

Dado que deseamos aclarar de qué "tipo de cosa" se ocupa un tratamiento psicoanalítico, y cómo puede lograr lo que intenta, nos importa subrayar ahora que en el fondo de lo que un paciente aduce cuando recurre al psicoanálisis, siempre encontraremos un conflicto entre fuerzas en pugna que se inscriben en las categorias del deber, el poder y el querer. Un conflicto que ha conducido hacia un desequilibrio entre las magnitudes de esos tres parámetros que encuadran la existencia pática. Es un desequilibrio que a veces afecta al carácter de una persona, cuando una de las tres maneras -sea cardíaca, hepática o cerebral- funciona con un exagerado predominio o menoscabo frente a las otras dos. 
Cuando la conducta (hepática), que ejercita el poder, predomina, porque se descuidan los influjos del deber y del querer, se vive atrapado en un círculo vicioso que se derrumba inexorablemente conduciendo al inevitable sentimiento de que el poder no alcanza. Podemos verlo en los tiranos que oprimen a los pueblos que gobiernan, pero también algunas veces en los hombres de negocios cuando proceden en la forma que suele describirse con la expresión "hígado frío".

Cuando se obedecen los influjos del querer (cardíaco) sin reparar en los límites del poder y en los que establece el deber, se ingresa igualmente en un círculo de retroalimentación positiva (que Bateson (1990) denominó esquismogenético) que conduce a la frustración y el fracaso. Podemos verlo en las personalidades infantiles que se rigen por caprichos, pero también en las personas que se entregan a los dictados del corazón "sin usar la cabeza".

De manera análoga, cuando el deber como norma (cerebral) desestima y anula los requerimientos del poder y del querer, aumentan los sentimientos de culpa que se intenta "echar afuera" y que ocultan la impotencia. El malestar que se genera de ese modo crece de manera continua. Podemos verlo en los moralistas inflexibles que, entregados a una justicia ciega y desmesurada que ignora los matices de la condición humana, concluye (como el inspector Javert en Los miserables, de Victor Hugo) en un dilema de conciencia que puede llegar a un extremo en el que se destruye la vida. Pero también en las personas que "se llenan la cabeza" con proyectos inalcanzables y viven continuamente torturadas porque jamás logran lo que "les hace falta".

\section{La transferencia de lo pasado en el presente}

Hemos visto que lo que el tratamiento psicoanalítico se propone es la conciliación del conflicto que condujo a la represión y al retorno de lo 
reprimido que, perturbado, se manifiesta en los síntomas que nos arruinan la vida. En cuanto a cómo lo logra, ya hemos adelantado una primera parte cuando señalamos que procura reactualizar el litigio escondido llevando nuevamente a la consciencia las fuerzas contradictorias en pugna.

La observación de lo que sucede en el tratamiento condujo a un descubrimiento muy importante que ha tenido una profunda influencia en el desarrollo de la técnica psicoanalitica. Suele decirse que los pueblos que no recuerdan su historia están condenados a repetirla, y el psicoanálisis descubre, poco a poco, ya durante los primeros intentos terapéuticos, precisamente eso, que el paciente "repite en lugar de recordar".

Los acontecimientos que no se recuerdan -entre los que cabe destacar los que fueron reprimidos junto con los sentimientos penosos que en su momento provocaron- no pierden completamente su fuerza por el hecho de permanecer inconscientes. Tienden, por el contrario, a reactualizarse y "se enlazan" -dice Freud en sus primeros trabajos sobre el tema de la transferencia- "a la persona del médico”, por el solo hecho, debemos agregar enseguida, de que él "está allï", "físicamente" presente.

En esos primeros trabajos Freud usaba la expresión "falso enlace", para referirse al hecho de que los vínculos que se establecen están impregnados con afectos e importancias que "no corresponden a la realidad presente", sino que provienen de la transferencia de las figuras paternas sobre los sustitutos actuales. Hoy, aunque sabemos que es imposible considerar que un enlace sea definitivamente verdadero, podemos continuar diciendo que, en un cierto sentido, un enlace es falso cuando podemos concebir otro que nos parece más adecuado a la situación actual.

Junto a esa transferencia inconsciente e inmediata, que forma parte de la vida cotidiana, y que es la misma que nos lleva a "pegar un portazo" cuando estamos enojados con alguien, el psicoanálisis descubre otra, que se denominó "neurosis de transferencia". La neurosis de transferencia se 
constituye gracias a que la transferencia evoluciona en "la relación con el médico" durante las diferentes vicisitudes del proceso. Esa transferencia inconsciente -que en un cierto sentido es neurótica- puede observarse en cualquier tratamiento médico (o en una relación semejante, como la que se establece, por ejemplo, entre un discípulo y su maestro). Pero la que se constituye en un tratamiento psicoanalítico evoluciona con características propias, debido al hecho de que el psicoanalista trabaja con ella, procurando acercarla a la consciencia.

Es frecuente oír -y no sólo entre los legos, sino también, a veces, entre algunos psicoanalistas- que se juzgue a un determinado colega según el grado de consideración que muestra frente a la realidad en la cual vive el paciente. Muchas veces se aduce que, en los casos en que las personas sufren por carencias muy penosas que suelen llamarse "reales", como la pobreza que deriva de la falta de un buen empleo, o el dolor que ocasiona la muerte de un hijo, necesitan, más que las interpretaciones de un psicoanalista, la ayuda solidaria y concreta de otro ser humano que les "tienda una mano".

Es cierto, sin duda, que los caminos de nuestro entorno pueden ser llanos y fáciles o, por el contrario, irregulares y plagados de circunstancias dificiles. Pero tampoco cabe duda de que transitaremos por ellos de muy distinta manera si los recorremos guiados por un mapa trazado con premisas equivocadas. Freud decía que el psicoanálisis nada puede hacer con los sufrimientos que son "normales" en la vida, pero que puede, en cambio, liberarnos de aquellos "neuróticos", que son innecesarios e inútiles. El psicoanálisis opera precisamente allí, sobre "el mapa" que nos guía, y contribuye a "corregirlo" cada vez que conduce a la consciencia una parte de la transferencia injustificada de lo pasado en el presente. La realidad que estudia el microbiólogo es la que coloca en la platina del instrumento que utiliza. La realidad que descubre el psicoanalista en su campo de trabajo reside, más que en las vicisitudes "reales" que el 
paciente relata, en "los pormenores" de las transferencias que surgen cuando nos relacionamos con él.

Señalemos por fin que al comenzar el tratamiento es frecuente una primera transferencia que deriva de experiencias de amparo y protección que provienen de la temprana infancia (y que investigaciones ulteriores remiten a la vida intrauterina). Esa transferencia, que atribuye al tratamiento la posibilidad "ideal" de otorgar un beneficio rápido sin mayores esfuerzos, pronto queda sustituida por una desilusión sobre la cual se transfieren experiencias frustrantes anteriores. Freud (2004a) afirmaba que el tratamiento sólo podía continuar si en ese mismo lapso de tiempo se desarrollaba una transferencia positiva que, facilitada por actitudes e interpretaciones atinadas del psicoterapeuta, contribuyera a sostenerlo pasando por encima de la desilusión.

\section{La consciencia de la transferencia inconsciente}

En una primera época del psicoanálisis su creador no creyó necesario ocuparse, durante el tratamiento, de llevar hacia la consciencia lo que el paciente transfería "sobre la persona del médico", excepto cuando esa transferencia contribuía para aumentar la resistencia. De modo que, mientras la persona psicoanalizada colaborara con el tratamiento concurriendo a las sesiones y comunicando sus asociaciones, el psicoanalista, en esa primera época, debía centrar su labor en comprender, a través de las actitudes, los gestos y las palabras del paciente, cuáles eran los afectos reprimidos que generaban los síntomas que alteraban su vida.

Freud descubrirá muy pronto que esa actitud es errónea, y que se debe prestar atención a la transferencia desde el primer momento. Su experiencia lo conduce a sostener que así como "nadie puede ser matado en ausencia o en efigie", la única posibilidad de que un conflicto se elabore hasta el punto en que se logra conciliar el litigio "original" es que se 
"batalle" en la relación con el médico -en la transferencia- con una suficiente participación afectiva. Más tarde descubriremos que, para que ese proceso se cumpla, esa participación afectiva debe ser tolerable, es decir que tampoco puede ser excesiva.

A pesar de la rotunda afirmación freudiana -y de los valiosos aportes posteriores de dos insignes psicoanalistas, Melanie Klein y Enrique Racker-, la práctica psicoanalítica predominante incurrió en un cierto descuido de los principios teóricos que condujo a continuar postergando cuanto fuera posible, durante los tratamientos, el "batallar" los conflictos en la transferencia. Un grupo más pequeño de psicoanalistas, dirigiendo su atención a lo que constituye la esencia del proceso psicoanalítico, se ocupó de interpretar la transferencia ya desde la iniciación del tratamiento. Una gran mayoría, en cambio, continuó centrando su labor en "aplicar" el psicoanálisis para esclarecer los afectos inconscientes que se manifiestan en la relación del paciente con las personas de su entorno.

Investigaciones ulteriores, motivadas por la necesidad de "dosificar" los afectos que surgen en el tratamiento, nos condujeron a proponer que el psicoanalista, mientras mantiene en su consciencia lo que el paciente siente en su relación con él, recurra al procedimiento de comunicárselo indirectamente, utilizando, por ejemplo, a las personas que forman parte de su relato. Debemos apresurarnos en aclarar que el uso de esta modalidad interpretativa no nos debe llevar a descuidar la primera parte (mantener en la consciencia lo que el paciente siente "en la relación con el médico"), porque ese descuido nos retornaría al ejercicio de un psicoanálisis "aplicado" que no presta suficiente atención a la transferencia.

No necesitamos ahora recorrer todos los jalones del itinerario que, a través de los años, aportó una creciente riqueza al concepto de transferencia. Bastará con referirnos a dos de esos jalones. El primero radica en el descubrimiento freudiano de que el médico "contratransfiere", 
lo cual significa que la transferencia es reciproca. El segundo lo encontramos en los trabajos de Racker (2000), que convierten la contratransferencia (ya sea que se manifieste como una repentina ocurrencia en el psicoanalista o como la "posición" que él adopta frente a su paciente) en un instrumento técnico.

También en ese territorio -como ocurrió con la transferencia- los conceptos fueron evolucionando desde una actitud inicial, en la cual el análisis de la contratransferencia se utilizaba únicamente cuando surgía como una perturbación de la tarea, hasta llegar a comprender que constituye el único recurso que nos permite interpretar lo que el paciente siente y qué es lo que transfiere.

Muchos años después, el descubrimiento de "neuronas espejo" permitió encontrar una representación física al fenómeno de las transferencias recíprocas. Hoy podemos decir que entre los seres que consideramos dotados de una vida anímica, y no sólo en un tratamiento psicoanalítico, cada uno de los protagonistas de una relación contribuye con sus propios afectos al "clima" que se establece en el vínculo, transfiriendo sobre el presente los productos de una experiencia anterior.

Más aún, hemos descubierto que el único acceso a la interpretación de las transferencias recíprocas que funcionan en una sesión de psicoanálisis se da en un "punto" de encuentro -el único posibleconstituido por la confluencia de dos "urgencias", la que opera en ese momento de la vida del paciente y la que, análogamente, opera como "resonancia" inevitable, pero también imprescindible, en el psicoanalista. Podemos entonces afirmar que el trabajo psicoanalítico no sólo cambia lo que ambos, el paciente y el médico, se transfieren recíprocamente, sino también lo que cada uno de ellos transfiere sobre los seres significativos que pueblan su entorno.

Llegamos a comprender, por ese camino, que (dado que la transferencias reciprocas se influyen mutuamente, y que lo que el psicoanalista interpreta -más allá de si lo habla o lo calla- modifica su 
contratransferencia) el "agente" terapéutico por excelencia reside en el hecho de que, aunque el paciente tiende a repetir una historia "en su relación con el médico", el psicoanalista funciona dentro de ella como un personaje inesperado que altera su sentido.

Los dos descubrimientos -el que se expresa diciendo que el conflicto debe ser elaborado en la transferencia, y el de que la transferencia es recíproca- fueron trascendentes. A partir de alli pudo distinguirse con mejor fundamento entre "aplicar" el psicoanálisis para comprender -con una escasa consciencia, en el médico, de su participación afectiva- lo que le ocurre al paciente "en su mundo"; y el verdadero proceso psicoanalítico, que ocurre empáticamente en la relación entre ambos, y que es el que le otorga la fuerza necesaria a "la palanca de cambio".

\section{Los árboles y el bosque}

Las cosas que nos suceden en la vida suelen parecernos particulares y distintas, y sin embargo, si las juntamos en racimos, descubrimos que remiten a unas pocas que siempre son las mismas, que se repiten una y otra vez en contextos diferentes. Al fin y al cabo, somos semejantes, y si no fuera por eso, viviriamos aislados en un mundo inabordable. Lo que acabamos de afirmar no evita que los detalles de algún particular disgusto que irrumpe desequilibrando nuestra existencia cotidiana y nos arruina un día, una semana o, a veces, se perpetua en años, puedan sorprendernos como una calamidad inesperada que, de acuerdo con lo que con frecuencia pensamos, tiene muy poco que ver con lo que somos.

Sabemos que los árboles pueden impedirnos contemplar el bosque, pero en nuestra tarea como psicoterapeutas a veces nos sucede que, en nuestro afán por mejorar el desarrollo de una rama, nos olvidamos del tronco que la nutre y perdemos de vista la salud del árbol. Por intenso que sea el sufrimiento con el cual un paciente recorre el drama "urgente" de un 
suceso puntual que lo atormenta, conviene evitar que nuestro deseo de ayudarlo nos distraiga de los asuntos que están en la raíz.

Dijimos antes que uno tiende naturalmente a repetir en lugar de recordar, y que, en la medida en que lo que se repite perjudica, la tarea del tratamiento debe consistir en procurar que el paciente recuerde en lugar de repetir. De más está decir que en aquello, reprimido, que no se recuerda, y que cuando se repite perjudica, encontramos la raíz de donde surgen los dramas que aquejan al paciente.

Vale la pena reproducir aquí unas palabras de Gandhi, porque iluminan de manera sencilla cómo llega a constituirse ese "núcleo" perjudicial inconsciente: Cuida tus pensamientos, porque se transformarán en actos; cuida tus actos, porque se transformarán en hábitos; cuida tus hábitos, porque determinarán tu carácter; cuida tu carácter, porque determinará tu destino; y tu destino es tu vida.

Ya nos hemos referido al hecho de que el paciente, sin tener plena consciencia de lo que le sucede, transfiere sobre la relación que establece con su psicoanalista - configurada con los pormenores que forman parte del proceso psicoterapéutico- los detalles de un drama "pretérito" que también suele transcurrir en el presente con alguna de las personas de su entorno. Suele pensarse entonces, a partir de ese hecho indiscutible, que nuestra tarea principal consiste en llevar a la consciencia del paciente que él transfiere sus sentimientos desde una relación, en la cual han surgido, a otra, actual, con el médico, que juzga semejante, aunque no siempre lo sea. Señalemos, de paso, que no conviene insistir demasiado en este último punto, porque a veces la relación es semejante, y lo importante reside, en cambio, en que los afectos que el paciente pone en juego no son adecuados.

Debemos reparar en el hecho de que, aunque el paciente puede enriquecer su consciencia acerca de sí mismo descubriendo que transfiere, lo esencial -en lo que ahora decimos- no reside en ese punto. Entre los sentimientos que en la sesión se transfieren sobre el psicoanalista, algunos 
son conscientes, aunque, mientras tanto, puede permanecer inconsciente el hecho de que son transferidos. Esos sentimientos transferidos que actualmente son conscientes también lo fueron en los conflictos con su entorno que durante la sesión nos relata. Por eso es necesario subrayar que lo esencial de lo que ahora señalamos no reside en que los afectos conscientes son transferidos, sino, por el contrario, en que suelen ser inadecuados en la medida en que se los utiliza para encubrir otros que permanecen ocultos.

Alli debemos entonces apuntar, a ese otro estrato inconsciente y latente, resistido que, tal como lo ha señalado Racker, también es el producto de una transferencia que "se esconde detrás" de la que opera como resistencia. Porque es el lugar en donde moran las disposiciones afectivas que el paciente reprime, inhibe y substituye con sintomas, con conductas erróneas, o con otros afectos que la situación no justifica.

Nos queda por aclarar en este punto una última cuestión. A pesar de que llevar hacia la consciencia del paciente un afecto o un significado reprimido puede enriquecer su comprensión de lo que le sucede, es importante reparar en que eso no es suficiente para obtener el cambio duradero de actitud que puede conducirlo a superar alguna de las dificultades por las que recurre al tratamiento.

Los "complejos" -es decir, el conjunto de ligámenes entre sentimientos e ideas, preformados como hábitos de pensamiento o de conducta que funcionan como malentendidos- se comportan como malformaciones sostenidas por múltiples "raíces" que se manifiestan en distintas circunstancias. De modo que el esclarecimiento (el insight) que una interpretación produce sobre un determinado asunto debe repetirse una y otra vez (elaborarse) en cada uno de los puntos en los que el "tumor" se "arraiga" (o se manifiesta), para lograr, por fin, que se disuelva. Agreguemos, además, que lo que una interpretación acertada logra llevar a la consciencia tiende a volver rápidamente a lo inconsciente. Por eso es 
necesario insistir en que el trabajo en las sesiones es un trabajo "de hormiga" que debe repetirse, de una manera continuada y minuciosa, para alcanzar "el día" en que se obtiene un cambio irreversible.

\section{El campo en el que se realiza la tarea}

Podemos vivir apuntando hacia la verdad, la realidad, la autenticidad y la actualidad, o hacia la mentira, la ilusión, la falsedad, y también hacia la historia de un ayer que ya no es. Podemos vivir "en lo que somos", o -cuando damos por cumplido el deseo de ser lo que ahora no somos- podemos vivir imaginando ser algo distinto que, quizás, una vez fuimos. Verdad y mentira, realidad y delirio o ilusión, autenticidad y falsedad, son oposiciones que encierran un campo intermedio entre la actualidad y la historia, que funciona impregnado por la transferencia del pasado en el presente.

Se constituye de ese modo, en un continuo "viaje de ida y vuelta" entre la percepción de lo que somos y la imagen de lo que deseamos, o tememos ser, la experiencia de un "como si lo fuéramos". Ese campo intermedio configura una tercera manera de vivir que podemos observar en el teatro, o en el juego, y que forma una parte esencial de una sesión de psicoanálisis. Tal como sucede cuando vamos al teatro o jugamos un partido de tenis, en donde un conjunto de "ilusiones" que no suelen ser conscientes nos lleva a sentirnos de un modo diferente cada vez que ganamos o perdemos, allí vivimos una suerte de ficción, "a medias creída". Así habitamos ese campo que transita entre la vida que llamamos "real" y el enlace "ficticio" con una historia que en esa realidad fingida "se repite". Es muy importante agregar aquí algo que Freud nos ha permitido comprender: en el tratamiento psicoanalítico la transferencia conduce a una repetición, pero también, como ocurre con el teatro y con el juego, y como producto de una especie de "reedición" modificada de lo que ya se ha 
vivido, el proceso puede traducirse en un cambio de lo que en lo sucesivo se transfiere.

Una parte de la sesión de psicoanálisis constituye una suerte de teatro en el cual -por obra de las transferencias recíprocas- el paciente y el psicoanalista funcionan como una persona que "se presenta" representando a otra. Ese teatro -en donde todo ocurre "como si" algo que "no es" fuera "real"- se ubica, en cada situación particular aisladamente considerada, a una distancia variable entre ambos extremos: la realidad y la ficción. De modo que, a pesar del proverbio que afirma que "del dicho al hecho hay mucho trecho", en un momento dado "el enlace" que la transferencia recorre conduce, cuando el trecho se acorta, hacia experimentar lo que se vive como un hecho "real", y en otro, cuando se alarga, a experimentarlo como "una forma de decir", como una historia que se cuenta sintiendo que es ficticia.

Podemos afirmar que el tratamiento psicoanalítico se realiza a la manera del tejido de una urdimbre, y que el paciente y el psicoanalista, mientras recorren un curso progresivo, oscilan, juntos o separados, entre ambas oposiciones, abandonando a veces la historia para ingresar en la vida real, y otras veces la vida real para ingresar en la historia. En el trabajo psicoanalítico con las transferencias recíprocas, la dificultad fundamental surge cuando el paciente o el psicoanalista o, peor aún, ambos, permanecen unilateralmente atrapados, o "fijados", en uno de esos dos extremos que, como ocurre frecuentemente con los extremos, se tocan en el punto en el cual la resistencia triunfa.

La resistencia a permitir que lo reprimido penetre en la consciencia puede manifestarse como hostilidad y antipatía (transferencia "negativa") o como un deseo de amor (transferencia "erótica") que pretende sustituir el propósito original que motivó la relación que se establece con el psicoanalista. Lo que debía funcionar como un "teatro" queda confundido, entonces, con una realidad de la vida que transcurre impregnada por una 
turbulencia emocional (producto de lo que suele denominarse una "transferencia masiva"). Encontramos un ejemplo de ese último aspecto de la transferencia en lo que ocurre cuando dos adolescentes que han comenzado a jugar a que pelean ingresan paulatinamente en una contienda cada vez más real, que transcurre con dolor, con miedo y con hostilidad crecientes. Un juego deja de ser juego cuando se quebrantan sus reglas, y lo mismo ocurre con el proceso psicoanalítico cuando se perturba su encuadre.

Cuando, en cambio, los afectos ocultos permanecen inconscientes e inhibidos -junto con el drama que el "teatro" no ha logrado convocar por el temor a que se despierten emociones incontrolables-, el tratamiento psicoanalítico se agota en el relato de historias que evocan afectos escasos o emociones que sustituyen a las reprimidas. Allí se toca el otro extremo, y el proceso psicoanalítico se convierte en un procedimiento exageradamente "intelectual" que esteriliza el tratamiento.

\section{El escenario y las reglas}

Durante los procesos de aprendizaje no sólo se adquiere la capacidad que se persigue, que se reintroducirá luego, de manera espontánea, en la vida del que aprende, en donde se constituye como un nuevo hábito automático inconsciente. También se aprende algo en general (que Bateson denominó deuteroaprendizaje) acerca de la manera de aprender. No cabe duda de que el fundamento principal del proceso psicoanalítico reside en que la vida real de ambos protagonistas se enriquece cuando, en vez de vivirla plenamente en la sesión, se procura contemplarla en el campo de las transferencias recíprocas, reintroduciéndola, de manera mesurada, en un acto de consciencia. Lo que aquí significa "de una manera mesurada" se comprende mejor si recordamos que el compromiso afectivo, que acompaña al proceso que conduce a la consciencia algo de aquello que se guardaba reprimido, debe 
cumplir con el doble requisito de ser suficiente y, al mismo tiempo, tolerable.

El tratamiento psicoanalítico, en cuanto configura un verdadero "encuentro" entre el paciente y su psicoanalista, forma una parte importante de sus vidas "reales", en las cuales influye. De modo que lo que ocurre en la relación entre los dos no sólo debe ser contemplado desde el campo teatral -o lúdico- de la situación analítica. Por el contrario, tal como sucede en el teatro o en el juego, deben trazarse y mantenerse en la conciencia las coordenadas (temporales y espaciales) de un encuadre que constituye el escenario del teatro y las reglas del juego. Así como un científico establece un encuadre cuando, para realizar una estadística, homologa las variables, o el cirujano respeta las reglas que aseguran la asepsia, el psicoanalista debe fijar un encuadre para "limpiar" el campo de observación dentro de cual trabaja.

El encuadre, con su escenario y sus reglas, forma parte de la vida real, de modo que cabe subrayar ahora que no solamente con las reglas "no se juega", sino que constituyen un campo adicional del proceso analítico. En ese campo "adicional" se vive una experiencia que les ocurre al paciente y al psicoanalista "en realidad" y de una vez para siempre. Es un territorio que puede y debe ser continuamente registrado mientras se contempla el campo "teatral" de la sesión de psicoanálisis. Por eso decíamos antes que el "teatro" de la situación psicoanalítica sólo constituye una parte del "campo" en el cual se realiza la tarea. No sólo es necesario descubrir la influencia de la transferencia en los acontecimientos de la vida real, sino también de qué manera los acontecimientos de la vida real influyen en la evolución de la transferencia, dado que, al fin y al cabo, son dos vertientes de un mismo proceso.

Un juego deja de ser juego cuando se quebrantan sus reglas, y lo mismo ocurre con el proceso psicoanalítico cuando se perturba su encuadre. Sin embargo, tanto el quehacer teatral como la teoria de los 
juegos nos brindan la posibilidad de comprender un espacio creativo que proviene de la importancia (jmesurada!) puesta en juego y que se ejercita en la distinción entre la trampa burda y la introducción de una variante que renueva su interés.

En el mundo animal (tal como lo ha señalado Bateson) los cachorros que juegan comunican que no muerden "en serio" porque simultáneamente mueven la cola mostrando un estado de ánimo que no refleja hostilidad. Sólo la capacidad específica del autor teatral le permite saber cuándo puede ingresar un personaje al escenario desde la platea, aumentando el afecto comprometido sin destruir el campo de ficción imprescindible para el ejercicio del teatro.

Dijimos antes que el tener en cuenta la magnitud del compromiso emocional nos proporciona un parámetro para encontrar la mesura que buscamos. Debemos subrayar ahora, desde otro ángulo, que encontrarla no sólo depende de la capacidad de movilizar una "pequeña magnitud" de afecto que permite que los procesos de simbolización puedan ser utilizados para ejercer el pensamiento, sino también de la posibilidad de movilizar una cantidad suficiente para brindar aquello que proporciona (de acuerdo con lo que sostiene Susan Langer, 1958) un cierto grado de plenitud a la función simbólica.

Freud sostuvo que los procesos psíquicos funcionan de dos modos. Uno, primario, que condensa y desplaza, con magnitudes plenas, la importancia que atribuye a los sucesos. Es un proceso que, sin un cuidado suficiente de su justificación, se traduce en una equiparación de los símbolos con lo que simbolizan. Hanna Segal (1982) denominó "ecuación simbólica" a esa "confusión" (cuyo paradigma es la psicosis) que conduce, por ejemplo, a relacionarse con la palabra "pan" como si fuera el alimento que designa. Otro, secundario, que funciona con magnitudes pequeñas y caracteriza a los procesos del pensamiento racional que establecen diferencias (razones) y proceden con símbolos saludablemente constituidos. 
Debemos reconocer, sin embargo, que ambos procesos se "combinan" para generar ese campo "intermedio" del cual nos estamos ocupando, y que constituye el territorio en el cual se desarrolla la tarea que se propone acercar a la consciencia las transferencias reciprocas. Ese modo "terciario" que funciona como un tránsito fugaz entre los procesos que el psicoanálisis denomina primario y secundario (dificilmente perceptible, como ocurre con los cambios catastróficos), ha sido descripto con diferentes nombres por distintos autores. Es el "lugar" en donde ocurre la gestación de los símbolos y, de acuerdo con lo que escribe Charles Peirce, gracias a su operación pueden ocurrir la metáfora, el sueño, la parábola, la alegoría, todo el arte, toda la ciencia, toda la religión, y toda la poesía.

\section{La importancia de no jugar con el encuadre}

No cabe duda, entonces, de que el primer requisito esencial de toda técnica psicoanalítica consiste en establecer el encuadre dentro del cual se realizará la tarea. Una disposición importante de ese encuadre radica en que el paciente se recline en el diván y el analista se siente detrás. Freud señalaba que facilitaba su tarea el poder trabajar sin que lo incomodara el hecho de que la persona que debía psicoanalizar pudiera mirarlo intentando percibir sus impresiones. Podemos, sin embargo, sostener que la razón fundamental reside en que un paciente, que acostado y distendido, no dirige su atención hacia el entorno, puede contemplar mejor los pensamientos que espontáneamente se le ocurren y que derivan de sus impulsos reprimidos.

Contribuye a mantener esa situación ("enviar en dirección retrógrada los procesos de excitación") el hecho de que durante la relación y el diálogo que se establece con el terapeuta, se tienda a evitar (regla de la abstinencia) que los impulsos se deriven en acciones. Por los mismos 
motivos, conviene que la respuesta a las palabras que el paciente pronuncia, o a las solicitudes que realice, se reduzca, hasta donde se pueda, a un mínimo imprescindible.

También forma parte del encuadre el modo en que el psicoanalista cobra el dinero que recibe como retribución de su labor. Freud (op. cit.) recomendaba cobrar los honorarios de una manera franca, directa y exenta de ambigüedades. Se ocupó, además, de la cuestión, insistiendo en la importancia de asumir dos actitudes. Cuando esas dos actitudes no son bien comprendidas, suele pensarse que reflejan una rigidez innecesaria que no tiene en cuenta las dificultades que pueden presentarse en la vida del paciente.

Aconsejaba cobrar los honorarios a intervalos regulares $y$, en definitiva, ese consejo se concreta, en la mayoría de los casos, en que se pague lo que se adeuda cada mes. El fundamento esencial de esa actitud más allá de si se respeta lo convenido en forma rigurosa o con cierta flexibilidad- consiste en que, periódicamente, se cancele la deuda en su totalidad, sin dejar cabos sueltos que modifiquen en la práctica los acuerdos que fueron convenidos sobre principios claros. También recomendaba dejar establecido que el paciente mantiene reservado un tiempo de su psicoanalista, y que debe pagar las sesiones que contrata aunque se justifiquen los motivos que le impiden concurrir a una cita convenida.

Cuando no se perciben adecuadamente los principios que fundamentan la importancia de esos dos consejos, suele pensarse, como ya dijimos, que reflejan una rigidez innecesaria. Si agregamos ahora que, además, en el fondo, muchas veces se la considera injusta, se comprende mejor que de ese modo se incurra con frecuencia en algunos de los "fáciles desvíos" que esterilizan la tarea psicoanalitica. Subrayaremos enseguida los principios que motivan lo que Freud recomienda, pero antes debemos señalar que las actitudes que Freud aconsejaba sólo parecen injustas 
cuando se las contempla de un modo superficial. Algunas de las críticas que suelen oírse ilustran la cuestión.

A veces se sostiene que si el paciente se ve obligado a programar sus vacaciones en una fecha que no coincide con las de su psicoanalista es injusto que no goce de los mismos derechos. Pero reparemos en que es innegable que una cosa es elegir el momento en que se tomarán las vacaciones, y otra distinta es pagar las sesiones que no se utilizan. Cuando se alquila una vivienda, por ejemplo, el locatario no pretende dejar de pagar el alquiler durante el lapso de tiempo en que se va de vacaciones. Conviene reparar en el hecho de que un psicoanalista que respeta los parámetros de un encuadre adecuado a las necesidades del proceso compromete una parte considerable de su agenda y, por consiguiente, cuando un paciente interrumpe el tratamiento sin cancelarlo, le deja vacante una parte importante del tiempo que destina a su trabajo sin otorgarle la libertad de ocuparlo con otra persona.

Otras veces se aduce un argumento similar al de las vacaciones cuando un acontecimiento que no depende de la voluntad del paciente le impide concurrir a su sesión de psicoanálisis. Se piensa de manera diferente, sin embargo, cuando una persona compra un objeto en un bazar y, luego de salir del negocio, alguien se lo roba. Nadie pretende en ese caso que el vendedor se lo reponga sin volver a pagarlo.

Debemos volver ahora sobre los motivos que sostienen las dos actitudes que (en lo que atañe al pago de los honorarios) deben formar parte de las reglas del "juego" que constituye nuestro campo de trabajo. Esos motivos surgieron de la necesidad de disminuir las ocasiones que se producen cuando un paciente, mientras realiza "acciones" que son un importante producto de la transferencia, da por sentado que no pertenecen al territorio en donde lo que ocurre se debe, o se puede, psicoanalizar.

La importancia que aquí subrayamos radica en que cada uno de los detalles de la relación entre un paciente y su psicoanalista termina siendo, 
muchas veces, el "lugar" en donde los afectos transferidos se traducen en acciones que "la realidad" aparentemente justifica, y se substraen, de ese modo, de la posibilidad de analizar qué significan. Si una ley estableciera decía Freud- que en una determinada plaza de la ciudad no se permite que la policía aprese a los ladrones, no debería extrañarnos que en un tiempo breve todos ellos se refugien alli.

La actitud que asumimos cuando la persona que psicoanalizamos expresa su transferencia, de manera inconsciente, mediante alteraciones del encuadre (pagando, por ejemplo, los honorarios con retraso), es muy importante. En esas circunstancias podemos interpretar en silencio los significados inconscientes de una transgresión, pero si incluimos esos fundamentos en el enunciado de nuestras interpretaciones, aceptamos, implícitamente, el uso de la transgresión como una forma legítima de lenguaje. Por ese motivo, si queremos evitar que el paciente continúe "jugando" con las reglas del juego, no nos queda otro recurso que elegir entre dos opciones. Aceptar el cambio, si se juzga tolerable, sin pretender comunicarle al paciente lo que significa como expresión de la transferencia o, por el contrario, establecer firmemente que se trata de una transgresión inaceptable.

\section{Los fáciles desvios}

Debemos ocuparnos, por fin, entre las distintas disposiciones del encuadre, de la que constituye el lugar en donde la resistencia encuentra un refugio con mayor frecuencia. Freud, en La iniciación del tratamiento (op. cit.), recomienda comenzar con seis sesiones por semana y aclara que luego de que el análisis adquiere un buen ritmo se pueden reducir a tres. Es cierto que en la primera época, anterior al descubrimiento de que era necesario psicoanalizar el carácter, y no sólo los síntomas, los tratamientos se sustanciaban en unos pocos meses. Pero, tal como lo afirma el creador del psicoanálisis, mientras un tratamiento largo y 
frecuente sea mejor que otro breve y más fácil, habrá que optar por el primero.

En un comienzo trabajaba en reuniones de dos horas, pero luego prefirió reducir el tiempo a la mitad. El deseo de establecer un pequeño intervalo entre las sesiones condujo muy pronto a la costumbre, que hoy comparte la mayoría de los psicoanalistas, de que duraran cincuenta minutos. Un insigne psicoanalista francés, que generó muchos discípulos, Jacques Lacan, acostumbraba trabajar en reuniones más cortas, que solía finalizar cuando lograba una interpretación satisfactoria. La experiencia enseña, sin embargo, que es necesario disponerse a compartir con el paciente los momentos en que "nada sucede" -que muchas veces aburren y abruman a los dos integrantes del encuentro- porque suelen preceder a la emergencia de pensamientos, o de interpretaciones, "protegidos" por una intensa resistencia.

Es fácil darse cuenta de que la frecuencia semanal es un requisito compartido por otros procedimientos que, como sucede con el entrenamiento o con el aprendizaje, ponen en juego procesos que tienen algo en común. Sin embargo, en la inmensa mayoría de las psicoterapias actuales se acepta, con la excusa, absurda, de que es mejor algo que nada, que el paciente elija la frecuencia que más le complace. Para colmo, cuando se lo formula en inglés, once a week, por ejemplo, el asunto adquiere visos de seriedad científica. Nada tiene de malo que un paciente y su médico limiten su propósito al ejercicio de un procedimiento distinto y se conformen con los resultados que obtienen. Lo malo reside en que suele aducirse que esas otras formas de la psicoterapia son psicoanalíticas, conduciendo a que se desvalorice, o se ignore, el alcance terapéutico del psicoanálisis.

¿De qué depende, entonces, que se piense diferente cuando se trata de la dosis de un fármaco, de la continuidad y frecuencia de un entrenamiento deportivo, de un proceso de aprendizaje, o de una 
rehabilitación neuromuscular? ¿No admitimos, acaso, que es absurdo que un enfermo interrumpa prematuramente la ingestión de un antibiótico y en lugar de aniquilar a los microbios los "vacune"?

No caben demasiadas dudas de que, del lado del paciente, influyen las resistencias que despierta el hacer consciente lo inconsciente. Resistencias en cierto modo similares suelen presentarse en procedimientos que -como las dietas, los entrenamientos o los aprendizajes- deben muchas veces luchar contra los hábitos que, en algunas ocasiones, funcionan como verdaderas adicciones. Del lado del médico, es imposible desconocer el hecho de que -por desgracia- son muchos los que, atrapados por resistencias semejantes, prefieren adaptarse a lo que más abunda en el mercado y eligen cobrarle más por menos tiempo a un paciente que, cuando se desilusione, será más fácil remplazar.

El motivo que más se utiliza para eludir la frecuencia semanal de sesiones que el psicoanálisis requiere es que no se dispone de suficiente dinero para enfrentar lo que cuestan; y cuando la situación económica holgada no permite utilizar ese argumento, el paciente suele recurrir a la idea de que no puede sustraer ese tiempo a las ocupaciones irrenunciables que rellenan su vida. De vez en cuando, sin embargo, aparece un motivo que nos acerca a una reflexión más profunda. Algunas personas aducen que si realizaran sesiones con la frecuencia que el psicoanalista les propone, se les acabarían los temas, y no sabrian, entonces, de qué podrian hablar. ¡Pero, precisamente, cuando se aduce ese motivo, es porque "se sabe algo que se ignora saber"! Podriamos decir, extremando el asunto, que cuando "los temas" se acaban, el verdadero psicoanálisis comienza, porque surgen entonces los pensamientos resistidos e insólitos que lo inconsciente arroja desde la urgencia de una insatisfacción reprimida.

En el adulto, mucho más que en el niño, los intervalos de dos o tres días entre las sesiones permiten rellenarlas con la hojarasca constituida 
por los detalles de sucesos aparentemente importantes, que repiten, una y otra vez, el intento de postergar lo esencial para un momento ulterior. Tal vez fue por este motivo (que difiere del que en su momento se adujo) que un conjunto de psicoanalistas que se agruparon en torno a Melanie Klein propugnaban realizar las sesiones en forma cotidiana de modo que quedaran separadas por un solo intervalo semanal.

Entre los fáciles desvíos de la trayectoria fructífera quizás pueda decirse que es ese el principal, pero no debemos omitir dos importantes. Uno, que en realidad ya hemos mencionado, es el psicoanálisis "aplicado" a interpretar, desde "afuera", y desde una posición intelectual que no compromete suficiente afecto, lo que ocurre en la vida de un paciente que proyecta sobre su psicoanalista la imagen de un gurú que se las sabe todas y al cual es imprescindible consultar cada vez que se necesite decidir. El otro funciona como una especie de "pacto" que mantiene indefinidamente una situación invariante dentro de la cual el paciente, sin el menor esfuerzo, resulta ilusoriamente confortado y protegido mientras cumpla con los requisitos formales que se han convenido.

\section{La construcción de un baluarte}

Si bien es cierto que el psicoanálisis nació, durante el estudio de la histeria, como un intento de comprender y de curar sus síntomas, muy pronto, y a medida en que se fueron incluyendo otros trastornos, se fue consolidando una cuestión que fue adquiriendo, de manera progresiva, una mayor claridad. El procedimiento no podia ofrecer demasiadas garantías a menos que se dirigiera, decididamente, hacia el psicoanálisis del carácter, constituido por el conjunto de hábitos que determinan la forma en que una persona percibe, siente y procede.

Es claro que, mientras que los sintomas perturban al paciente $\mathrm{y}$ quiere liberase de ellos, con el carácter ocurre que, en su mayor parte por 
lo menos, suele ser lo que se dice "egosintónico". Con esa palabra, no sólo queremos referirnos a que la consciencia no lo registra como algo que molesta, sino también a que forma una parte indistinguible de la propia identidad. Sin embargo, para evitar que los trastornos que aquejan al paciente se perpetúen, o sean sustituidos por otros condicionados por los mismos factores, es necesario que el psicoanálisis incluya los rasgos del carácter, que surgen, una y otra vez, durante el tratamiento y se manifiestan en las transferencias reciprocas.

Un sintoma aparece como algo carente de significado, algo de lo cual procuramos desprendernos. Frente a los rasgos de carácter, en cambio, solemos pensar "yo soy así". Si decimos que ese pensamiento obstruye el progreso y que el psicoanálisis muestra que el carácter se configura de esa manera, y no de otra forma, por motivos definidos que, en principio, pueden ser psicoanalizados como se psicoanalizan los síntomas, enunciamos una afirmación que, inevitablemente, despierta una cierta antipatía.

Así sucede que, cuando se trata de lograr que los síntomas desaparezcan, contamos con la colaboración del paciente, pero cuando procuramos influir para modificar algún rasgo de los que constituyen su carácter, y a pesar de que muchas veces la persona que psicoanalizamos nos dice que es ese su deseo, tropezamos con una resistencia fuerte. Se comprende fácilmente si tenemos en cuenta que, aun en los extremos de la melancolía, uno ama su manera de ser, construida con esfuerzo a lo largo de la vida. Las personas que suelen recurrir a la cirugía estética para obtener algunos cambios leves en la forma de su nariz no desean que se les cambie la cara con la que presentan su identidad ante el mundo.

$\mathrm{El}$ "problema" radica en que muy pronto el psicoanalista (y también a veces el paciente, pero con una convicción menor) llega a comprender que para realizar el tratamiento que le han solicitado necesita dirigir su tarea hacia la modificación del carácter. Los signos de la dificultad no se hacen esperar. Cuando una persona que recurre al psicoanálisis 
experimenta como un acoso intolerable todo aquello que siente como algo que cuestiona su manera de ser, construirá un "baluarte", lo más inexpugnable que pueda, en torno de lo que siente que necesita a toda costa defender. Esto no nos extraña, porque sabemos que funciona, con la eficacia de un automatismo aprendido, cada vez que la experiencia actual reactiva alguna historia antigua que dejó, como enseñanza, la capacidad para identificar las señales ("angustia señal”) que anuncian la inminencia de una angustia intensa ("angustia catastrófica").

La antipatía que denominamos transferencia negativa se presenta, entonces, puntualmente a la cita. Nuestro paciente no se sentirá comprendido y con frecuencia se volverá escurridizo. Incurrirá en silencios que producen desasosiego, aburrimiento o, inclusive una somnolencia patológica (que Fidias Cesio describió como letargo). Otras veces intentará "distraernos" con relatos farragosos y con detalles que "no deben ser interrumpidos". Cuando la cuestión arrecie, reaccionará intentando modificar el encuadre: le molestará utilizar el diván, no concurrirá a las sesiones, llegará tarde, o propondrá disminuirlas, y lo que predomine en sus sentimientos hacia su psicoanalista será una cierta hostilidad.

Es obvio que no debemos o, peor aún, ni siquiera podemos arremeter a pie firme contra el bastión que el paciente construye. ¿Cómo podremos entonces ayudarlo? Cuando deciamos, antes, que los afectos que surgen durante el tratamiento no sólo deben ser suficientes, sino que también deben ser tolerables, describíamos las conclusiones que nos condujeron a dos recursos que son claves para dosificar el afecto.

Uno, que ya hemos mencionado, es la interpretación "indirecta", que nos permite, por ejemplo, utilizar los personajes del relato para llevar a la consciencia del paciente los afectos ocultos, en un momento en que le sería muy difícil admitir que los está transfiriendo sobre el psicoanalista. El otro consiste en que, a pesar de que es imprescindible que el psicoterapeuta pueda identificarse "complementariamente" con las 
personas con las que el paciente convive, no se debe descuidar jamás la necesidad de mantener en la consciencia, de modo permanente, lo que el paciente siente "aquí y ahora", y sobre todo, que somos, en alguna medida, semejantes.

Esa unión entre la consciencia de lo que "el otro" siente y la consciencia de nuestra semejanza con él es lo que denominamos identificación concordante, y nos otorga, como recurso técnico, la posibilidad de formular las interpretaciones utilizando la palabra "uno" para referirnos a lo que tenemos en común. La identificación concordante equilibra de esa manera, a través de la "simpatía", la "antipatía" que la mayor parte de las veces acompaña a la identificación complementaria.

Un recurso y el otro -la interpretación "indirecta" y la identificación concordante- funcionarán mejor si realizamos nuestra tarea recordando que psicoanalizar requiere prudencia, resignación y paciencia. Entre esas tres actitudes, la que más nos duele es la resignación.

Resignarse frente a una persona que hubiéramos querido poder ayudar mejor no sólo significa renunciar, sino que también lleva implícito volver a trazar, cada día, el rumbo de lo posible. Pero para lograrlo, debemos atrevernos a estimar continuamente "el ángulo" de nuestra derrota y aceptar "hasta donde" pudimos, ya que constituye una condición necesaria para "recalcular" lo que quizás podremos.

Es muy duro reconocer los límites de nuestra potencia, porque nos amenaza el doloroso recuerdo de las veces que fracasamos en nuestro deseo de salvar algo que amamos. Tan duro como para preferir, con frecuencia, construir la culpa del "no quise", que nos ayuda a negar la impotencia del "no pude". Para adquirir la capacidad de resignarnos es imprescindible, entonces, que atravesemos, una y otra vez, ese proceso de duelo por nuestras ilusiones perdidas que, aunque finalmente nos alivia, primero, siempre, nos obliga a sufrir.

\section{El psicoanálisis interminable y los puntos de urgencia}


Dado que el carácter es un conjunto de hábitos que determinan la forma en que se percibe, se siente y se procede, nada tiene de extraño que en el camino hacia la desaparición de los sintomas -que el psicoanálisis emprende motivado por la solicitud del paciente- se tropiece con la inevitable necesidad de psicoanalizar algunos rasgos del carácter. Realizar esa tarea implica llevar a la consciencia las fuentes inconscientes, "olvidadas" hace ya mucho tiempo, que ayer originaron lo que hoy se repite con la fuerza de un hábito que no se cuestiona (ya que ponerlo en entredicho conduce al colmo de la angustia). Agreguemos enseguida, entonces, que psicoanalizar una modalidad perjudicial del carácter no es tarea sencilla. No sólo porque una costumbre que se consolida como un rasgo consubstanciado con la identidad tiende a mantenerse de manera inmutable, sino también porque los rasgos no son entes aislados; por el contrario, se entrelazan, unos con otros, en una especie de "complejo" que les otorga un equilibrio recíproco. Modificar un rasgo lleva implícito, por ese motivo, desestabilizar a otros miembros -algunos de los cuales pueden ser valiosos- de la "familia" de modalidades que conforman el estilo con el cual una persona vive.

De más está decir que esa nueva orientación de la tarea que el psicoanalista emprende condujo a que los tratamientos, que en los comienzos se sustanciaban en meses, se fueran prolongando progresivamente, ya que psicoanalizar un rasgo de carácter implica reconocerlo, una y otra vez, en diferentes contextos. Cuando Freud aborda ese tema (en Análisis terminable e interminable, 2004b), también introduce la cuestión de en qué momento, y en qué punto, un tratamiento puede dar por cumplido su propósito.

Una de las objeciones más frecuentes que adopta la resistencia que el procedimiento despierta consiste en afirmar que dura demasiado tiempo. También, a veces, se aduce que, una vez iniciado, genera una dependencia que impide interrumpirlo. Recordemos que Freud señalaba 
que mientras la eficacia de un tratamiento largo sea mayor que la de otro más corto, deberemos optar por el primero. Así se procede en otras ramas de la medicina. Frente a un paciente al cual se le ha extirpado la glándula tiroides, frente a un diabético, o frente a un hipertenso, por ejemplo, los procedimientos que habitualmente se aconsejan no se eligen por su duración, sino por la eficacia que, muchas veces, los trasforma en necesarios.

Debemos reparar en que la dependencia, como una condición ineludible en cualquier organismo que "respira", en sí misma, no constituye un perjuicio. "Sentir" la dependencia significa, muy por el contrario, registrar la realidad. Vivimos inmersos en un entorno afectivo que limita nuestros derechos cuando colisionan con los derechos ajenos. En ese entorno compartido, la ilusión "individualista" de ser autosuficiente constituye una pretensión ingenua y peligrosa.

Es necesario reconocer que el tratamiento psicoanalítico no crea la dependencia que observamos, por ejemplo, en el consumo de drogas que generan el apego a una sustancia dañina que cada vez alivia menos y deteriora más. Cuando el tratamiento se realiza como un acto médico idóneo y honesto, a lo sumo permite que allí se escenifique lo que ya existía (como una dependencia saludable o insalubre) en la relación del paciente con su entorno afectivo.

No es exagerado decir que vivimos "cableados" con los seres que pueblan nuestro mundo, y que así evolucionamos, conformando nuestra identidad como partes de una red que nos trasciende. Cuando, forzados por una realidad ineludible, o llevados por la ilusión de huir de las dificultades que tenemos, "cortamos" esos cables -como ocurre, por ejemplo, al emigrar de un país para ingresar en otro-, nos enfrentamos con un intenso desarraigo que altera el sentido de nuestra vida y nos obliga a un proceso de duelo que suele ser dificil.

Con frecuencia se sucumbe a la tentación de negar que sólo podemos ser siendo con otros. Hoy sabemos que vivimos interconectados 
en una red (autopoiética) que -como Internet- "se construye a sí misma", imbuida de un espíritu comunitario cuyos designios muy pocas veces intuimos, porque no podemos percibirla más allá del ámbito constituido por nuestra convivencia con los vecinos de nuestro entorno local. Es en esa convivencia, inseparable de lo que configura nuestra vida, en donde surgen las dificultades que se traducen en sintomas y que el tratamiento psicoanalítico procura mejorar.

El paciente, transfiriendo lo pasado en el presente, "pone en escena", en cada sesión de psicoanálisis, la dificultad que más lo apremia en ese instante, y lo hace en el interjuego con la transferencia recíproca del psicoanalista, configurando de ese modo ese campo teatral privilegiado en donde el encuadre y lo que se interpreta crean las condiciones para que una bienhechora transformación de los significados que se transfieren pueda suceder. Así, lentamente, mientras el paciente, en sus sesiones, va recorriendo el camino que lo lleva desde un apremio que lo oprime a la urgencia de otro apremio, el procedimiento progresa gracias a que en el entretejido de las transferencias recíprocas, confluyen los "puntos de urgencia" de los dos protagonistas.

Cuentan que Napoleón le decía a su valet: "Vísteme despacio, que estoy apurado", y debemos reconocer que el tratamiento funciona mejor cuando se emprende sin prisa y sin pausa. Nada puede apresurarlo, porque sólo allí, en esa confluencia que le otorga un afecto suficiente, las palabras que el psicoanalista pronuncia florecen, lentamente, en la transformación que se buscaba. Detrás de la cortina que las urgencias cotidianas agitan se van divisando entonces, poco a poco, los grandes asuntos, aquellos que obtienen su sustento en la manera de ser y proceder que denominamos carácter.

Antes de finalizar este apartado, debemos señalar que, entre los rasgos perjudiciales del carácter, hay uno que vale la pena mencionar especialmente, porque las características del encuadre psicoanalítico 
contribuyen para que pase con frecuencia desapercibido. Esa especie de "escotoma central" del encuadre se produce porque su regla fundamental establece que en las sesiones el paciente hable, sin ninguna censura voluntaria, de todo lo que de manera espontánea se le ocurre. Nos parece entonces natural que nos hable continuamente de "sus" intereses, y eso contribuye para que no prestemos atención a un rasgo de su carácter que, aunque puede quedar disimulado por el encuadre, también se manifiesta en la relación que se establece con el psicoanalista. Esas circunstancias colaboran, entonces, para que no reparemos en que algunos pacientes adolecen de un menoscabo muy importante en su capacidad para interesarse en las personas con las cuales conviven y no logran percibir adecuadamente lo que los otros sienten. Puede ocurrir, por ejemplo, que una persona con esos rasgos de carácter, comience su sesión hablando de alguna de sus contrariedades habituales, sin prestar atención al hecho de que su psicoanalista lo atiende afónico y resfriado.

\section{E1 trabajo del paciente}

Durante las primeras fases del desarrollo intrauterino (etapa blastocística) nos alimentamos sin el menor esfuerzo digestivo. Luego, a través de la sangre que nos llega por el cordón umbilical, recibimos oxígeno y alimento con un trabajo funcional muy pequeño. Apenas nacidos, la situación cambia de manera dramática y, para no abundar demasiado en los detalles de la "pérdida multifacética" que experimentamos, sólo diremos, como paradigma, que nos vemos obligados a tolerar que el alimento nos llegue a intervalos que no siempre coinciden con la urgencia de nuestras necesidades.

Hace ya algunos años (Chiozza et al., 2008) nos ocupamos de lo que numerosos autores afirman acerca del "desvalimiento" (neoténico) del ser humano durante su prolongada infancia, que cumple con la función de dar lugar a importantes cambios evolutivos. Nacemos "inmaduros" y con 
una mayor necesidad de asistencia ajena que la que se observa en otras especies, pero eso nos otorga una mayor posibilidad de transformarnos aprendiendo capacidades nuevas.

Durante los primeros años de nuestra infancia, cuando necesitamos algo, lloramos, y si todo funciona bien, los adultos que nos asisten nos comprenden y satisfacen nuestras carencias. Cuando un niño tiene una edad de tres años, nada es más fácil, para un padre, que comprarle un nuevo helado para remplazar al que se le ha caído. Cuando en cambio, a los dieciocho años, se deprime y llora porque su novia ya no lo ama, sus progenitores no pueden, como el hada madrina de la Cenicienta, transformar un zapallo en carroza.

Es así que, poco a poco - si todo funciona bien-, nuestros reclamos a la asistencia ajena, lejos de limitarse a llorar o rezar, pidiendo "ya hecho" lo que necesitamos, van evolucionando, progresivamente, hacia la adquisición de las habilidades -y de las responsabilidades- que requiere "hacerlo". En esos nos ayudan (como parte del proceso que se llama educación) nuestros progenitores. Ellos aprueban o desaprueban nuestros trabajos premiando, desde la función materna, nuestros esfuerzos independientemente de si se materializan en logros- y, desde la función paterna -coincidiendo con lo que hará la sociedad en la cual crecemos-, únicamente nuestros resultados.

La cuestión "viene al caso", porque suele suceder que, como consecuencia de algún menoscabo en el proceso que esquemáticamente describimos, el paciente sienta que necesita que el tratamiento transcurra en "un ritmo" distinto del que el psicoanalista, supuestamente, determina de una manera arbitraria. Sin embargo, y a pesar de lo que la persona que se psicoanaliza puede llegar a sentir, el encuadre del proceso psicoanalítico siempre será "postnatal", en el sentido de que las sesiones trascurrirán, de un modo inevitable, en algún horario que ambos, de común acuerdo, han elegido. 
A veces el paciente se lamenta porque, a la hora de su sesión, hubiera preferido no acudir y, en cambio, la hubiera necesitado el día anterior, en un momento en que lo atormentaba una crisis de angustia. También, en algunas ocasiones, puede suceder que se queje porque, olvidándose de que el horario es el producto de un acuerdo entre ambas partes, se siente obligado a concurrir. Tampoco es raro que le disguste que una sesión termine en la mitad de un diálogo que hubiera deseado continuar. Recuerdo que, hace muchos años, un paciente terminaba todas sus sesiones produciendo el chasquido que habitualmente se emite para expresar una contrariedad -presionando con la lengua el paladar superior y separándola bruscamente- y que parece representar de manera adecuada la reacción de un lactante cuando su madre le retira bruscamente el pezón que succiona.

Tal como, en forma esquemática, lo hemos consignado, la educación que faculta para relacionarse de un modo saludable con las normas que la realidad, la sociedad y la convivencia imponen es un proceso que configura el carácter, y que se recorre, desde la infancia a la adultez, en distintas etapas. Se comprende, entonces, que el "grado" que una persona haya alcanzado en ese recorrido condicione hasta qué punto, si recurre al psicoanálisis, experimentará como una injusta obligación alguna de las incomodidades que el encuadre "le impone".

Más allá del disgusto que esas incomodidades ocasionan, durante el tratamiento suele surgir, en distintas proporciones, un malentendido que es importante señalar. Hay procesos, como la extirpación de un apéndice infectado, en que la colaboración del paciente se limita a contratar al cirujano y concurrir al quirófano, en donde será operado mediante una anestesia general, y se enterará del resultado cuando, finalizado el proceso, despierte. Hay otros, como aprender a tocar el violín, en que el resultado no sólo requiere contratar un buen maestro y concurrir puntualmente a sus clases, porque depende, de muy fundamental manera, del trabajo del alumno. A pesar de que parece obvio que un tratamiento 
psicoanalítico se parece más al proceso por el cual se aprende un habilidad compleja que al otro, quirúrgico, en el cual intervenimos menos, la observación demuestra que las personas que lo emprenden tienden, con frecuencia, a negar que su trabajo es esencial, refugiándose en la idea de que, una vez contratado e iniciado el tratamiento, su parte se ha cumplido, y que todo dependerá, desde luego, de la capacidad y la dedicación de su psicoanalista.

Por razones cuya exposición excede el propósito de este artículo, podemos decir que la época en la cual hoy vivimos, que aproxima el esfuerzo y el trabajo a la idea de castigo y de condena, se presta especialmente para favorecer, avalando desde un consenso público erróneo, el malentendido que señalamos, y que también podemos observar en otros contextos que requieren dedicación y compromiso. Mencionaremos, sin embargo, un factor fundamental en la configuración de un malestar que es típico de nuestra época.

El proceso educativo, que acontece de manera espontánea y natural cuando crecemos armoniosamente dentro de una familia saludable, no sólo nos prepara para la convivencia ("civil") con los seres que habitan nuestro entorno, sino que contribuye para conformar y sostener el espíritu de la comunidad que habitamos. Una parte de ese espíritu (que configura lo que denominamos cultura, urbanidad o civilización) es un conjunto de "buenas costumbres", de preceptos morales, de normas, que constituyen la realidad "normativa" de la sociedad que habitamos y que -cuando funcionamos bien- acompaña a nuestra percepción de una realidad objetiva y a nuestra adecuada sensibilidad frente a una realidad emocional subjetiva. Cuando, en cambio, ese proceso educativo adolece de debilidades importantes, el lugar en donde el trastorno se manifiesta en una forma más clara es en la actitud que adoptamos frente a la realidad normativa. 
Agreguemos, entonces, y a pesar de las limitaciones que todo esquema conlleva, que si la psicosis puede ser contemplada como una alteración "alucinatoria" de la realidad perceptiva, que es "física y objetiva", y la neurosis puede ser entendida como una distorsión emocional, "ilusoria" de la realidad sensitiva, que es "anímica y subjetiva", la psicopatia, que en nuestra época abunda y crece hasta configurar casi un signo de nuestro tiempo, puede ser vista como una transgresión "perversa" de una realidad que, constituida por un conjunto de normas morales, es "espiritual y colectiva".

\section{Referencias bibliográficas}

Bateson, G. (1990). Naven. "Un ceremonial Iatmul". Barcelona: Júcar. (Original publicado en 1958).

Bateson, G. (1991). Pasos hacia una ecología de la mente. Una aproximación revolucionaria a la autocomprensión del hombre. Buenos Aires: Lohlé-Lumen. (Original publicado en 1972).

Cesio, F. R. (1960). El letargo. Una contribución al estudio de la reacción terapéutica negativa. Revista de Psicoanálisis, 17: 10-26.

Chiozza, L.; Busch, D.; Corniglio, H.; Obstfeld, M. y Pinto, M. (2008). "Los significados inconcientes de la función tiroidea”. En Luis Chiozza. Obras Completas. Tomo XII (1993-1997). Afectos y afecciones 3. Los afectos ocultos en la enfermedad del cuerpo. Buenos Aires: Libros el Zorzal. (Original publicado en 1997).

Chiozza, L. (2009). Corazón, hígado y cerebro. Tres maneras de la vida. Buenos Aires: Libros el Zorzal.

Freud, S. (2004a). "Trabajos sobre técnica psicoanalítica"; en Obras Completas, tomo XII. Buenos Aires: Paidós. (Originales publicados entre 1911 y 1915). 
Freud, S. (2004b). "Análisis terminable e interminable" en Obras Completas, tomo XXIII. Buenos Aires: Paidós. (Original publicado en 1937).

Langer, S. K. (1958). Nueva clave de la filosofia. Un estudio acerca del simbolismo de la razón, del rito y del arte. Buenos Aires: Sur. (Original publicado en 1941).

Ortega y Gasset, J. (1963). "El hombre a la defensiva". En Obras Completas, tomo II. Madrid: Revista de Occidente.

Racker, H. (2000). Estudios sobre la técnica psicoanalítica, la transferencia y contratransferencia. México: Paidós. (Original publicado en 1960).

Segal, H. (1982). Introducción a la obra de Melanie Klein. Madrid: Paidós. (Original publicado en 1964).

Weizsäcker, V. (2005). Patosofia. Buenos Aires: Libros el Zorzal. 